\title{
The Effect of Flapless and Full-thickness Flap Techniques on Implant Stability During the Healing Period
}

\author{
Mohammed Jasim AL-Juboori ${ }^{1, *}$ and Shafluzan Bin AbdulRahaman ${ }^{2}$ \\ ${ }^{1}$ Department of Oral Surgery, MAHSA University, Malaysia; ${ }^{2}$ Lecturer, Department of Oral and Maxillofacial Surgery, \\ University Sains Malaysia, 16150, Kelantan, Malaysia
}

\begin{abstract}
Purpose: When soft tissue flaps are reflected for implant placement, the blood supply from the periosteum to the bone is disrupted. The aim of this study was to compare the effects of the flapless (FL) and full-thickness flap (FT) techniques on implant stability. Methods: Nine patients received 22 implants. The implants were placed using the FL technique on the contralateral side of the jaw; the FT technique was used as the control technique. Resonance frequency analysis (RFA) was performed at the time of implant placement and at 6 and 12 weeks after implant placement. RFA values were compared between the FL and FT groups and between time intervals in the same group. Results: The median (interquartile range [IQR]) RFA values at the time of implant placement were 75.00 (15.00) for the FL technique and 75.00 (9.00) for the FT technique. At 6 weeks, the median (IQR) values were 79 (3.30) for the FL technique and 80 (12.70) for the FT technique. At 12 weeks, the median (IQR) values were 82.3 (3.30) for the FL technique and 82.6 (8.00) for the FT technique. There were no significant differences between the 2 techniques at the time of implant placement, after 6 weeks or after 12 weeks, with $p$ values of $0.994,0.789$, and 0.959 , respectively. There were significant differences between the RFA values at the time of implant placement and after 6 weeks for the FL technique $(\mathrm{p}=0.028)$ but not for the FT technique ( $p=0.091$ ). There were also significant differences between the RFA values at 6 weeks and the RFA values at 12 weeks for the FL technique $(\mathrm{p}=0.007)$ and for the FT technique $(\mathrm{p}=0.003)$. Conclusion: Periosteum preservation during the FL procedure will speed up bone remodeling and result in early secondary implant stability as well as early loading.
\end{abstract}

Keywords: Flapless, full-thickness flap, osseointegration, periosteum, resonance frequency analysis, stability.

\section{INTRODUCTION}

Endosseous dental implant stability can be defined as the capacity of the implant to withstand loading in the axial, lateral, and rotational directions [1]. The primary stability of dental implants depends on contact between the bone and implant during the surgical placement of the implant, and this mechanical contact can be obtained through the fixation of a press-fit structure into a bony cavity [1-3]. The degree of primary stability after implant placement is also dependent on bone quality, implant design, patient characteristics, bone density, implant diameter, implant site, and surgical technique $[1,4]$. The cortical/cancellous ratio of local bone is extremely important for implant stability at the time of implant placement and for determining the quality of local bone conditions, and optimal bone conditions are critical for implant success $[5,6]$.

In the weeks following the placement of an endosseous implant, primary mechanical implant stability is gradually replaced by biological stability [1]. When soft tissue flaps are reflected for implant placement, the blood supply from the soft tissue to the bone (supraperiosteal blood supply) is also removed, leaving only poorly vascularized cortical bone. The preservation of bone vascularization through use of the

*Address correspondence to this author at the MAHSA University, Dental Faculty, Block E, $4^{\text {th }}$ floor, pusat bandar damansara, damansara height, 50490, Kuala Lumpur, Malaysia; Tel: (+60)0162417557;

E-mail: doctor_mohamed_2006@yahoo.com flapless (FL) technique may help to optimize bone regeneration around implants, while full-thickness flaps (FTs) demonstrate high bone resorption after surgery [7]. A previous study showed that all partial-thickness flaps demonstrated bone regeneration at 3 and 7 days, while none of the fullthickness flaps demonstrated osseous regeneration [8]. Another study measured implant stability at the time of implant placement and after 3 months of healing in both flap and flapless cases. However, no significant difference in implant stability was noted between the 2 groups [9].

Non-invasive methods should be developed for assessing peri-implant bone height and implant stability $[10,11]$. Resonance frequency analysis (RFA) values can be used as an indicator for the early diagnosis of primary stability and can also provide useful information regarding the secondary stability of an implant $[12,13]$. Mean ISQ values during the second and third weeks are typically decreased significantly when compared with ISQ values at the time of implant placement [14].

The aim of this study was to evaluate implant stability during periosteum disruption and with periosteum preservation and to compare implant stability during different healing periods using a resonance frequency Osstell ${ }^{\mathrm{TM}}$ Mentor device.

\section{MATERIALS AND METHODOLOGY}

The protocol used in this study was approved by the Research and Ethics Committee of the School of Medical Sciences, University Sains Malaysia, Kubang Kerian, Kelantan 
(USMKK/PPP/JEPem/[200.3 (6)]; March $9^{\text {th }} 2008$ ). In this randomized controlled clinical trial, the outcomes of two flap techniques were compared in a split-mouth design. One implant was placed in one quadrant of the jaw to serve as the experimental group (FL), and another implant was placed in a similar location in the contralateral jaw quadrant to serve as the control group (FT) (maxilla or mandible) during the same surgical appointment.

The inclusion criteria were as follows:

1 - Bilateral posterior missing teeth in the same jaw of a single patient.

2 - Sufficient attached gingival keratinized tissue to support an adequate attached tissue cuff around the implant.

The exclusion criteria were as follows:

1 - The patient's treatment plan indicated the need for immediate implantation.

2 - Presence of a narrow alveolar ridge such that there was less than $2 \mathrm{~mm}$ of bone around the implant.

3 - Presence of a healing extraction socket (less than 4 months of healing time).

4 - Need for alveolar bone grafting or maxillary sinus lift.

All procedures to be performed were explained verbally and in writing to the patients, and all patients signed an informed consent form for the implant placement procedure.

Follow-up was scheduled for 6 and 12 weeks after implant placement for data collection.

A study cast was fabricated to evaluate the vertical and horizontal alveolar ridge dimensions and the amount of keratinized tissue in the edentulous area. OPG X-ray images were also obtained to evaluate the vertical bone height and vital anatomical structures. All of the implants had a regular neck with a length of $10 \mathrm{~mm}$ and a diameter of either $4.1 \mathrm{~mm}$ or $4.8 \mathrm{~mm}$ and were configured at ITI (SLA) Straumann ${ }^{\circledR}$ (Institut Straumann AG, Basel, Switzerland).

Randomization was achieved with a coin toss to determine whether the FL technique would be utilized on the left or right side of the mouth; the FT technique was then used in the contralateral jaw quadrant. Under local anesthesia (2\% mepivacaine hydrochloride with 1:100,000 adrenalin [Scandonest]; Septodont, France), a mid-crestal incision was performed longitudinally along the crest of the bone through the gingiva and the periosteum (Fig. 1).

Around the interdental papilla, an intrasulcular incision was made to separate the papilla into buccal and palatal papillae without thinning the papilla (Fig. 2), and a vertical incision was avoided (Figs. 3, 4). The appropriate implant position was selected and marked with a small round bur. Then, the implant beds were prepared with spiral drills of increasing diameters.

Tapping of the thread was performed on the recipient side in cases with normal bone density (class III), whereas no tapping was carried out in spongy bone (class IV). Implants were placed manually into their final positions using a ratchet, and the insertion torque was $20-35 \mathrm{Ncm}$. The implants were placed in a non-submerged fashion. A fine, 4-0 traumatic glyconate monofilament absorbable suture
(BRAUN, AESCLAP AG, CO., KG, Madrid, Spain) with a cutting needle was used for flap closure.

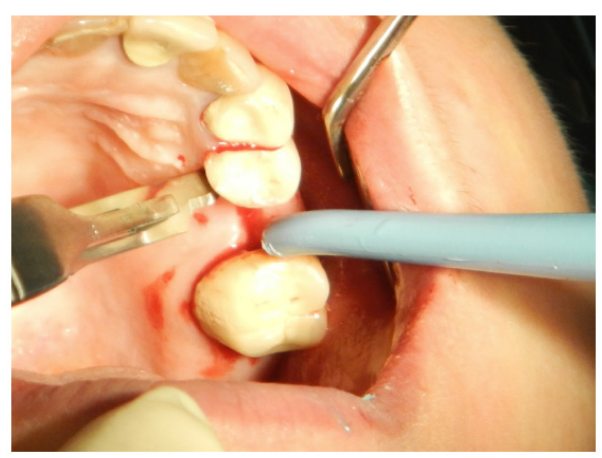

Fig. (1). The first step in flap design is a mid-crestal incision on the alveolar crest of the edentulous area.

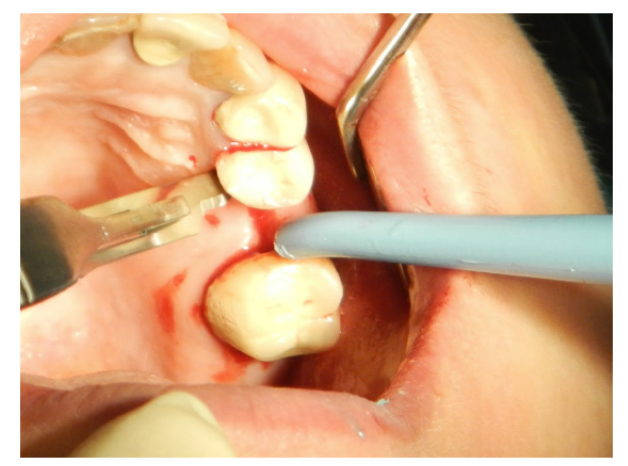

Fig. (2). The second step in flap design is an intrasulcular incision to cut the periodontium between the gingiva and the root surface on the marginal gingiva and the interdental papillae area.

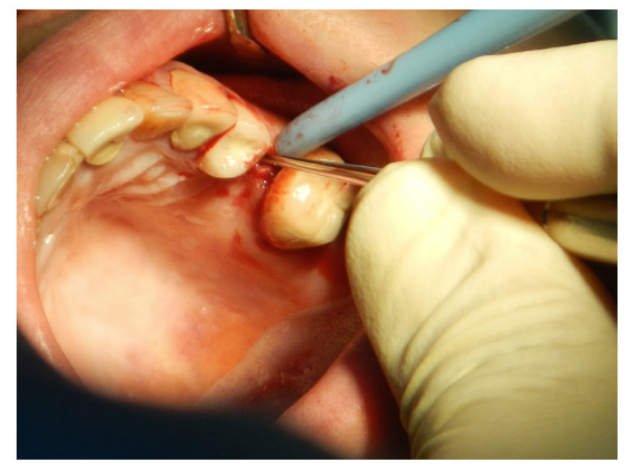

Fig. (3). Full thickness flap reflection starts with a crestal incision using a backward movement to reflect the palatal side. Care should be taken during flap reflection to ensure that the flap and adjacent soft tissue are not traumatized.

An interrupted suture was placed on the adjacent papillae for secure primary closure of the wound. After implant placement using the FT technique, the second implant was placed using the FL technique on the opposite side of the same jaw. The FL technique was performed using a manual disposable biopsy tissue punch (Nobel Biocare, Goteborg, Sweden) to create a circular excision through the soft tissue and periosteum (Fig. 5). Implant placement with the FL technique was carried out as in the FT technique following the recommendations of the implant system manufacturer. 


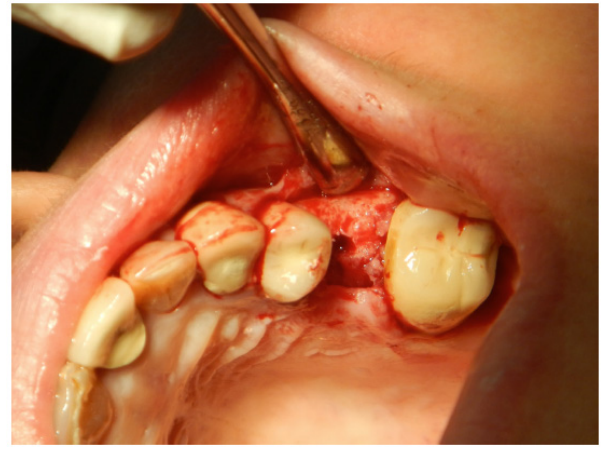

Fig. (4). Raising of the full thickness flap (including the adjacent papillae) without vertical incision. Sufficient bone is exposed to evaluate the bone width and to explore any potential bony undercut.

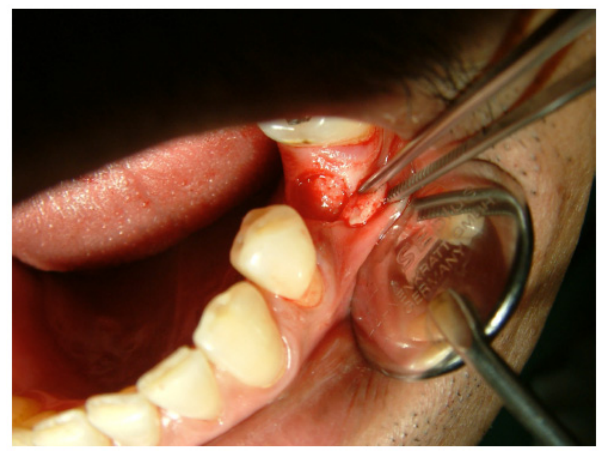

Fig. (5). Flapless technique (punch) by cutting the mucosa and periosteum until the bone.

The rigidity of implant-bone contact was measured by RFA (Osstell ${ }^{\mathrm{TM}}$ Mentor, Integration Diagnostic AB, Sweden). RFA measurements were obtained before the healing cape was screwed into the fixtures of the implants.

A Smartpeg (Smartpeg ${ }^{\mathrm{TM}}$, Integration Diagnostic AB, type 4 regular neck) was attached manually to the fixture with the aid of a mount, and a torque of 4-5 Ncm was applied. All measurements were carried out by the same investigator.

Implant stability was assessed clinically; if clinical, lateral, or rotational mobility were detected or the patient presented discomfort or pain during the process, the RFA measurements were not performed until the following visit $[15,16]$.

After the RFA measurements were performed, the ISQ value was recorded. To improve precision and assess repeatability, two additional ISQ values were obtained, and the Smartpeg was loosened and retightened for each measurement. A single representative implant stability value was computed by averaging the 3 ISQ values [16]. These measurements were performed at the time of implant insertion, after 6 weeks and after 12 weeks.

\section{RESULTS}

Nine patients (two males and seven females aged 27-62 years; median age 50 years) were included in this study.

In total, 22 implants were inserted. Each patient received two implants in a split-mouth design with the exception of two patients who received four implants (two in the mandible and two in the maxilla). The FL and FT techniques were used to place 11 implants each for a total of 22 implants.

Implants were placed in the mandible in 7 patients and in the maxilla in 3 patients. Most of the implants were placed in the mandibular molar area (Table 1).

None of the implants demonstrated rotational movement during cover screw removal or tightening for Smartpeg placement at 6 weeks into the healing process, which was a good indicator of implant stability.

All patients completed the 3-month follow up examination. Post-surgical wound healing was uneventful in all cases, and none of the cases were complicated by continuous pain, limited mobility, radiographic radiolucency or infection. The cumulative success rate was $100 \%$.

\section{RFA Values (ISQ units) at Implant Placement}

The implants placed in the mandible had higher primary stability and higher ISQ values than the implants placed in the maxilla.

The range of RFA values in the mandible was 60-84 ISQ units, and the median was 75 ISQ units, while the range of RFA values in the maxilla was 53-75 ISQ units with a median of 66 ISQ units (Table 2).

The median (IQR) RFA value for the implant placed via the FT technique was 75.00 (9.00) ISQ units.

The median (IQR) RFA value for the implant placed via the FL technique was 75.00 (15.00) ISQ units.

No significant differences in RFA values between the FL and FT techniques were detected $(\mathrm{P}=0.944)$ (Table 2).

\section{RFA Values (ISQ Units) After a 6-week Interval}

The median (IQR) RFA value for the implant placed via the FT technique was 80 (12.70) ISQ units, and the median (IQR) RFA value for the implant placed via the FL technique was 79 (3.30) ISQ units.

Implant stability did not significantly differ between implants placed via the FL and FT techniques after a 6-week interval $(\mathrm{P}=0.789)$ (Table 3).

\section{RFA Values (ISQ units) After a 12-week Interval}

The median (IQR) RFA value for the implant placed via the FT technique was 82.6 (8.00) ISQ units, and the median (IQR) RFA value for the implant placed via the FL technique was 82.3 (3.30) ISQ units.

Implant stability did not significantly differ between implants placed via the FL and FT techniques after a 12-week interval $(\mathrm{P}=0.959)$ (Table 4).

\section{DISCUSSION}

RFA is a non-invasive intraoral method designed to reflect the bone/implant interface. This method is useful for documenting clinical implant stability during the healing period and during routine follow-up $[11,17]$. 
Table 1. Distribution of dental implants in the mouths of patients.

\begin{tabular}{|c|c|c|c|}
\hline \multirow{2}{*}{ Type of flap } & \multicolumn{2}{|c|}{ Maxilla } & \multicolumn{2}{c|}{ Mandible } \\
\cline { 2 - 5 } & Molar area & Premolar area & Molar area \\
\hline \hline Flapless & 1 & 2 & 8 \\
\hline Full-thickness & 2 & 1 & 5 \\
\hline
\end{tabular}

Table 2. The median RFA values (ISQ units) at implant placement and at 6-week and 12-week time points for flap and flapless implants.

\begin{tabular}{|c|c|c|c|}
\hline Variable & $\begin{array}{c}\text { Flap } \\
\mathbf{n}=\mathbf{1 1} \\
\text { median (IQR) }\end{array}$ & $\begin{array}{c}\text { Flapless } \\
\mathbf{n}=\mathbf{1 1} \\
\text { median (IQR) }\end{array}$ & Z statistic $^{\text {P value }}$ \\
\hline \hline $\begin{array}{c}\text { RFA (ISQ) } \\
\text { 0 weeks }\end{array}$ & $75.00(9.00)$ & $75.00(15.00)$ & -0.070 \\
\hline $\begin{array}{c}\text { RFA (ISQ) } \\
\text { 6 weeks }\end{array}$ & $80(12.70)$ & $79(3.30)$ & -0.267 \\
\hline $\begin{array}{c}\text { RFA (ISQ) } \\
12 \text { weeks }\end{array}$ & $82.6(8.00)$ & $82.3(3.30)$ & -0.994 \\
\hline
\end{tabular}

${ }^{a}$ Wilcoxon signed rank test

* Significant difference $(\mathrm{p}<0.05)$

Table 3. The median RFA values (ISQ units) at implant placement (0 weeks) and at the 6-week time point for the flapless and flap techniques.

\begin{tabular}{|c|c|c|c|c|}
\hline Variable & $\begin{array}{c}\text { RFA(ISQ) } \\
\text { 0 weeks } \\
\text { median (IQR) }\end{array}$ & $\begin{array}{c}\text { RFA (ISQ) } \\
\text { 6 weeks } \\
\text { median (IQR) }\end{array}$ & Z Statistic $^{\mathrm{a}}$ & P value $^{\mathrm{a}}$ \\
\hline \hline Flapless & $75.00(15.00)$ & $79(3.30)$ & -2.191 & 0.028 \\
\hline Flap & $75.00(9.00)$ & $80(12.70)$ & -1.691 & 0.091 \\
\hline
\end{tabular}

${ }^{\mathrm{a}}$ Wilcoxon signed rank test

Table 4. The median RFA values (ISQ units) for bone at 6-week and 12-week time points for the flapless and flap techniques.

\begin{tabular}{|c|c|c|c|c|}
\hline Variable & $\begin{array}{c}\text { RFA (ISQ) } \\
\text { 6 weeks } \\
\text { median (IQR) }\end{array}$ & $\begin{array}{c}\text { RFA (ISQ) } \\
\text { 12 weeks } \\
\text { median (IQR) }\end{array}$ & Z Statistic $^{\mathbf{a}}$ & P value $^{\mathrm{a}}$ \\
\hline \hline Flapless & $79(3.30)$ & $82.3(3.30)$ & -2.705 & 0.007 \\
\hline Flap & $80(12.70)$ & $82.6(8.00)$ & -2.936 & 0.003 \\
\hline
\end{tabular}

${ }^{\mathrm{a}}$ Wilcoxon signed rank test

There were no significant differences in RFA values between the FL and FT techniques at the time of implant placement, indicating that there was no bias in the sites selected for implant placement.

Primary implant stability, which was achieved during surgical placement, was purely mechanical and resulted from the fixation of a press-fit structure into a bony cavity [2].

In this study, primary implant stability, which was measured by RFA during implant placement using the FL and FT techniques, was affected by bone quality, which ranged from type I (dense bone) to type IV (soft bone) according to the Lekhom and Zarb [18] classification.

Implants placed in the mandible had higher ISQ values than implants placed in the maxilla, especially in the maxillary molar area. This result is in accordance with other studies $[1,15]$. The ISQ values at the time of implant placement ranged from 60 to 84 ISQ units in the mandible and from 53 to 75 ISQ units in the maxilla.

Another factor that affected primary implant stability was bone tapping. Bone tapping before implant placement low- 
ered the RFA reading by at least 10 ISQ units. This result was often observed in type III bones and some type II bones.

At the 6-week time point, there were no significant differences in the RFA values obtained using the FL and FT techniques.

Implant stability at 6 weeks after the procedure was expected to be biological due to bone remodeling after implant placement. Following the placement of an endosseous implant, primary mechanical implant stability is gradually replaced by biological stability several weeks after placement [1]. This was observed in our study, as the RFA value obtained at 6 weeks was higher than that obtained at the time of implant placement using both the FL and FT techniques. This increase was statistically significant for the FL group but not for the FT group, which indicates that the bone remodeling rate in the FL group was faster than that in the FT group. This may be due to the rich blood supply that was provided by the preserved periosteum around the bone in the FL group, which can control bone turnover and bone formation around the implant $[19,20]$.

Other studies $[1,21]$ have examined the effects on the bone at different examination times. Ersanli et al $^{2}$ showed statistically significant increases in the ISQ values of implants after 6 weeks and correlated this phenomenon with the concept of enhanced bone formation around the implant surface at this time.

For implants with a higher initial stability (80 ISQ and above), the fluctuation in the median stability after 6 weeks was $<2$ ISQ. This result indicates a more consistent pattern of stability compared to the implants with lower primary implant stability, which showed progressive increases in implant stability.

These results are in accordance with another study [16] that showed fewer fluctuations in ISQ values for implants with a higher initial stability after 2-6 weeks.

It has been shown that implants inserted into bones with low density exhibited greater changes in RFA values than implants placed in high-density bones, such as those described in our study. This implies that implants placed in low-density bones could 'catch up' over time to reach levels equivalent to those of implants placed in high-density bones. There were no significant differences in RFA values between the FL and FT groups after 12 weeks; however, there was a significant difference between RFA values at 6 weeks and RFA values at 12 weeks for both the FL and FT groups.

These results indicate that bone remodeling and bone maturation were continuous in both groups during this period but may be higher in the flap group. This is in contrast to what we found after 6 weeks into the healing process, at which time the RFA values and implant stability were greater in the in the FL group.

From the $6^{\text {th }}$ to the $12^{\text {th }}$ week post-surgery, the mean ISQ value increased. This finding may be explained by the increased reinforcement from the woven bone scaffold that consists of lamellar bone.

A histological study [22] showed a sustained increase in bone implant contact after 6 weeks of healing, which corresponds to bone deposition by osteoblasts near the implant, resulting in bone formation around the implant. The evolution of the bone-implant contact that was observed histologically was comparable to the RFA value, which showed the same progression over time [22].

Implants with low primary stability (50-65 ISQ) required 12 weeks to reach an ISQ value of 80 , while implants with a higher primary stability (70 ISQ and above) needed less time (6 weeks).

This result is in agreement with another study that showed that implants with a lower RFA value due to a low initial stability required a longer healing period than those that were well-fitted [12].

Implants with a high primary implant stability at the time of surgery (ISQ values of 80 and above) had high values throughout the healing period and sometimes showed an increase in their ISQ value. This is in agreement with a previous study [23] indicating that high primary implant stability at the time of implant placement resulted in ISQ values that remained high during the healing period.

In our study, there were no significant differences in implant stability between implants placed via the FL and FT techniques during the healing period, which is in agreement with a study by Becker et al. [9]. This previous study showed no significant differences in implant stability between implants placed with the FL and FT techniques at the time of implant insertion and after 3 months.

The non-significant difference in implant stability between implants placed with the FL and FT techniques can be explained by a study by Grassi et al. [24], which showed the effect of sandblasted acid-etched implant surfaces on the bone-tissue response around the implant. The proliferation and differentiation of bone cells have been reported to be enhanced by the roughness of the implant surface topography, resulting in better bone-implant contact.

The current study showed an increase in RFA values for all implants during the 12-week healing period, even for the implants that were placed in soft bone. This may be due to the effect of sandblasted acid-etched surfaces, which enhance the quality of bone close to dental implants placed in soft bone.

The results of a study by Salvi et al. [25] showed that SLA improved bone-to-implant contact and led to higher Periotest values.

There was a difference in the primary stability between implants placed in the maxilla or soft bone and implants placed in dense bone or the mandible. Because the majority of implants were placed in the maxilla, this difference was not observed in the current study. In addition to the small sample size, this is one of the limitations of the present study.

The RFA values for implants that were placed in the maxilla or soft bone did not differ from those for implants placed in dense bone or the mandible at 6- and 12-week intervals, which may be due to the changes that occurred in the bone adjacent to the implant during the remodeling period. These changes included an increase in bone density around the implant, which does not differ between the maxilla and the mandible according to Grassi et al. [24]. Grassi et al. 
reported that the bone density was high in a $500-\mu \mathrm{m}$-wide zone lateral to the implant surface, suggesting that the sandblasted acid-etched surface may enhance the quality of bone close to dental implants placed in soft bone. This indicates that the density of bone surrounding the implant will be unified in all types of bone, in all implant systems that are coated with SLA, and on all sides of the implant, including the bucco-lingual or mesio-distal sides. Our study supports this notion, as the RFA reading at the time of implant placement in the bucco-lingual direction was less than that in the mesio-distal direction by approximately 2-3 ISQ units. However, the RFA reading was the same in both directions at the end of the $12^{\text {th }}$ week. Therefore, the RFA value can provide $3 \mathrm{D}$ information regarding the bone that surrounds the implant at the end of the healing period.

Cancellous bone in the mandible and maxilla had similar densities, whereas the cortical bone of the mandible was denser than that of the maxilla [26].

After implant placement, there will be changes in the rate of cancellous bone remodeling associated with changes in the blood supply that can also affect the bone remodeling rate. The increase in blood supply due to angiogenesis or arteriogenesis may explain the changes that occurred in cancellous turnover because trabecular bone is highly responsive to metabolic stimuli and has a turnover rate that is approximately three to 10 times higher than that in cortical bone, making it a prime site for detecting early bone loss and monitoring responses to therapeutic interventions [27].

The increase in cancellous bone remodeling will cause increases in bone mineral density and will lead to increases in secondary implant stability [27].

\section{CONCLUSION}

Periosteum preservation during the FL procedure will speed up bone remodeling and, in turn, result in early secondary implant stability and early loading.

\section{DISCLOSURE}

I would like to submit an original manuscript for consideration for publication. This manuscript is not under consideration for publication at any other journal, and I hereby disclose that myself and the other authors do not have any conflict of interest related to any products or materials mentioned in this article. This study had been funded by University Sains Malaysia.

\section{CONFLICT OF INTEREST}

Dr. Mohammed's work has been funded by University Sains Malaysia. Dr. Mohammed declares no conflict of interest.

\section{ACKNOWLEDGEMENTS}

We thank Mr. Mohammed Zaki Noor Al-Hashimi, a biostatistics lecturer at MAHSA University, for his great support and effort.

\section{REFERENCES}

[1] Mesa F, Munoz R, Noguerol B, de Dios Luna J, Galindo P, O'Valle F. Multivariate study of factors influencing primary dental implant stability. Clin Oral Implants Res 2008; 19: 196-200.

[2] Ersanli S, Karabuda C, Beck F, Leblebicioglu B. Resonance frequency analysis of one-stage dental implant stability during the osseointegration period. J Periodontol 2005; 76: 1066-71.

[3] Fanuscu MI, Chang TL, Akca K. Effect of surgical techniques on primary implant stability and peri-implant bone. J Oral Maxillof Surg 2007; 65: 2487-91.

[4] Glauser R, Sennerby L, Meredith N, Ree A, Lundgren A, Gottlow $\mathrm{J}$, Hammerle $\mathrm{CH}$. Resonance frequency analysis of implants subjected to immediate or early functional occlusal loading. Successful vs. failing implants. Clin Oral Implants Res 2004; 15: 428-34.

[5] Miyamoto I, Tsuboi Y, Wada E, Suwa H, Iizuka T. Influence of cortical bone thickness and implant length on implant stability at the time of surgery--clinical, prospective, biomechanical, and imaging study. Bone 2005; 37: 776-80.

[6] Pattijn V, Van Lierde C, Van der Perre G, Naert I, Vander Sloten J. The resonance frequencies and mode shapes of dental implants: Rigid body behaviour versus bending behaviour. A numerical approach. J Biomech 2006; 39: 939-47.

[7] Jeong SM, Choi BH, Li J, et al. Flapless implant surgery: an experimental study. Oral Surg Oral Med Oral Pathol Oral Radiol Endod 2007; 104: 24-8.

[8] Levin MP, Grower MF, Cutright DE, Getter L. The effects of length of surgery on healing of full and partial thickness flaps. J Oral Pathol 1977; 6: 152-60.

[9] Becker W, Wikesjo UM, Sennerby L, et al. Histologic evaluation of implants following flapless and flapped surgery: a study in canines. J Periodontol 2006; 77: 1717-22.

[10] Lachmann S, Laval JY, Jager B, et al. Resonance frequency analysis and damping capacity assessment. Part 2: peri-implant bone loss follow-up. An in vitro study with the Periotest and Osstell instruments. Clin Oral Implants Res 2006; 17: 80-4.

[11] Huwiler MA, Pjetursson BE, Bosshardt DD, Salvi GE, Lang NP. Resonance frequency analysis in relation to jawbone characteristics and during early healing of implant installation. Clin Oral Implants Res 2007; 18: 275-80.

[12] Huang HM, Chiu CL, Yeh CY, Lin CT, Lin LH, Lee SY. Early detection of implant healing process using resonance frequency analysis. Clin Oral Implants Res 2003; 14: 437-43.

[13] Al-Juboori MJ, Bin Ismail IH, Ab Rahman S. Dental implant stability and its measurement. Dent Implantol Update 2012; 23: 5761.

[14] Ab Rahmanm S, Al-Juboori MJ, Bin Ismail IH, Chandar PM. Dental implant stability from placement to loading. Dent Implantol Update 2012; 23: 61-4.

[15] Bischof M, Nedir R, Szmukler-Moncler S, Bernard JP, Samson J. Implant stability measurement of delayed and immediately loaded implants during healing. Clin Oral Implants Res 2004; 15: 529-39.

[16] Valderrama P, Oates TW, Jones AA, Simpson J, Schoolfield JD, Cochran DL. Evaluation of two different resonance frequency devices to detect implant stability: a clinical trial. J Periodontol 2007; 78: $262-72$.

[17] Huang HM, Lee SY, Yeh CY, Lin CT. Resonance frequency assessment of dental implant stability with various bone qualities: a numerical approach. Clin Oral Implants Res 2002; 13:65-74.

[18] Lekholm U, Zarb G. Patient selection and preparation. In: Bffmemark P-I, Zarb G, Albrektsson T, Eds. Tissue-integrated prosthesis: osseointegration in clinical dentistry. Chi-cago: Quintessence 1985; pp.199-209.

[19] Kemppainen P, Eskola S, Ylipaavalniemi PA. comparative prospective clinical study of two single-tooth implants: a preliminary report of 102 implants. J Pros Dent 1997; 77: 382-7.

[20] Traini T, Assenza B, San Roman F, Thams U, Caputi S, Piattelli A. Bone microvascular pattern around loaded dental implants in a canine model. Clin Oral Invest 2006; 10: 151-6.

[21] Machtei EE, Oved-Peleg E, Peled M. Comparison of clinical, radiographic and immunological parameters of teeth and different dental implant platforms. Clin Oral Implants Res 2006; 17: 658-65.

[22] Slaets E, Carmeliet G, Naert I, Duyck J. Early cellular responses in cortical bone healing around unloaded titanium implants: an animal study. J Periodontol 2006; 77: 1015-24. 
[23] Crismani AG, Bernhart T, Schwarz K, Celar AG, Bantleon HP, Watzek G. Ninety percent success in palatal implants loaded 1 week after placement: a clinical evaluation by resonance frequency analysis. Clin Oral Implants Res 2006; 17: 445-50.

[24] Grassi S, Piattelli A, de Figueiredo LC, et al. Histologic evaluation of early human bone response to different implant surfaces. J Periodontol 2006; 77: 1736-43.

[25] Salvi GE, Gallini G, Lang NP. Early loading (2 or 6 weeks) of sandblasted and acid-etched (SLA) ITI implants in the posterior mandible. A 1-year randomized controlled clinical trial. Clin Oral Implants Res 2004; 15: 142-9.

[26] Park HS, Lee YJ, Jeong SH, Kwon TG. Density of the alveolar and basal bones of the maxilla and the mandible. Am J Orthod Dentofacial Orthop 2008; 133: 30-7.

[27] Celenk C, Celenk P. Evaluation by quantitative magnetic resonance imaging of trabecular bone quality in the dentate and edentulous mandible. Clin Oral Implants Res 2008; 19: 15-18.

Received: April 29, 2015

(c) AL-Juboori and AbdulRahaman; Licensee Bentham Open.

This is an open access article licensed under the terms of the Creative Commons Attribution Non-Commercial License (http://creativecommons.org/licenses/by-nc/3.0/) which permits unrestricted, non-commercial use, distribution and reproduction in any medium, provided the work is properly cited. 